\title{
العوامل الخمس الكبرى للشخصية وعلاقتها باستخدام مواقع التواصل الاجتماعهي
}

شريف عبدالرحمن السعودي'، رقية مصبح المطرفي، الزهراء محمد الحسيني2، شمة مصبح المقبالي2

1أستاذ مساعد في القياس والتقويم- كلية الآداب والعلوم الإنسانية، قسم علم النفس- جامعة الشرقية- سلطنة عُمان

2طالبة بكالوريوس الإرشاد النفسي- كلية الآداب والعلوم الإنسانية- قسم علم النفس- جامعة الشرقية سلطنة عُمان

'Sharif.Alsoudi@asu.edu.om 


\section{العوامل الخمس الكبرى للشخصية وعلاقتها باستخدام مو اقع التواصل الاجتماعي}

\section{شريف عبدالرحمن السعودي، رقية مصبح المطرفي²، الزهراء محمد الحسيني²، شمة مصبح المقبالي²}

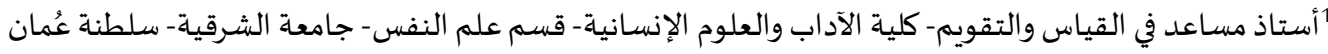

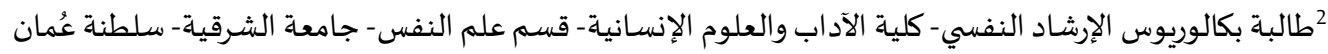
1Sharif.Alsoudi@asu.edu.om

DOI: https://doi.org/10.31559/EPS2021.9.3.6 2021/3/14 مراجعة البحث: 2021/3/21 قبول البحث: 2021/3/25 البحث

هدفت هذه الدراسة إلى الكشف عن طبيعة العلاقة بين العوامل الخمس الكبرى للشخصية، واستخدام مواقع التواصل الاجتماعي،

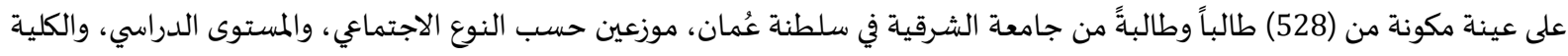

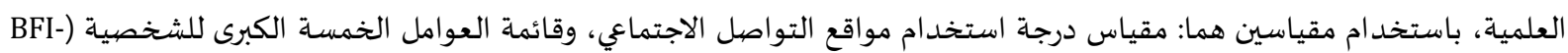

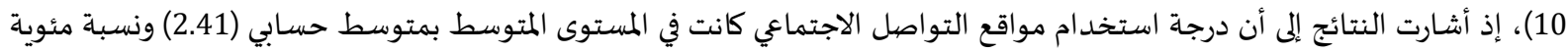

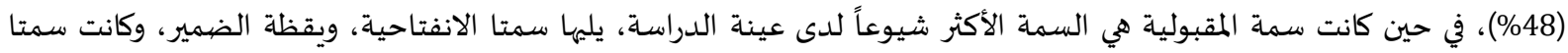

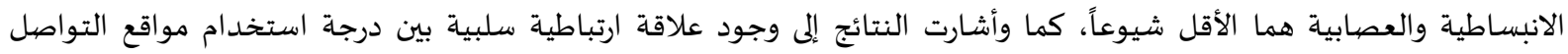

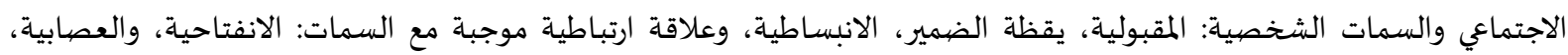
وأشارت نتائج تحليل الانحدار الخطي المتعدد المعياري إلى أن السمات الشخصية فسّرت ماتهية ما يقارب (27\%) من التباين في درجة استخدام

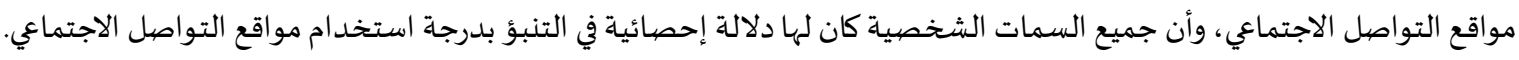
الكلمات المفتاحية: العوامل الخمس الكبرى للشخصية؛ مواقع التواصل الاجتماعي؛ الشخصية الإنسانية.

المقدمة:

تعد دراسة الشخصية الإنسانية من أهم المواضيع التي تناولها علم النفس، وأكثرها تعقيداً، إلا أنه يبقى أكثر مواضيع علم النفس حيوية، وقد

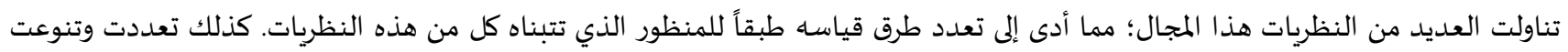

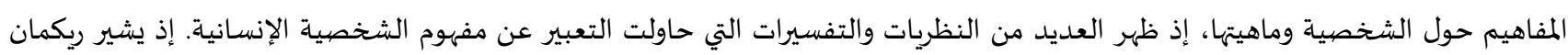

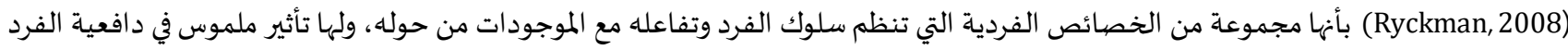

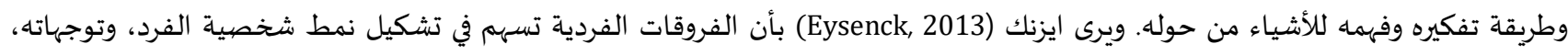

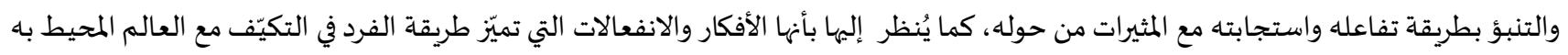

.(Santrock, 2011)

يعد نموذج العوامل الخمسة الكبرى للشخصية الذي طوره كوستا وماكري (Costa \& McCare, 1985) من أهم النماذج والتصنيفات التي فسّرت

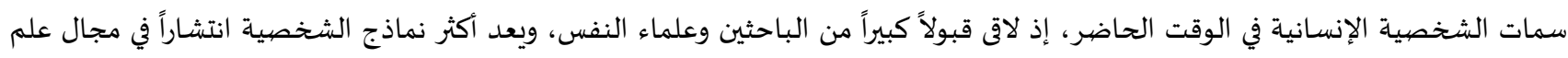

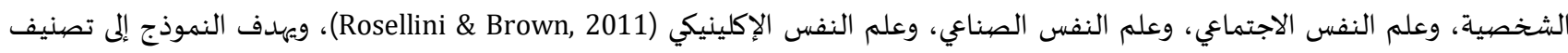
السمات الشخصية في خمس فئات أساسية، ويمتاز هذا النموذج بالثبات النسبي (Saucier, 2002)، ويشتمل على خمس سمات هي: 
1. الانفتاحية (Openness): ترتبط سمة الانفتاحية بالسمات التي تركز على أهمية الانفتاح على خبرات الأخرين ومشاعرهم، وتعكس مدى النضج

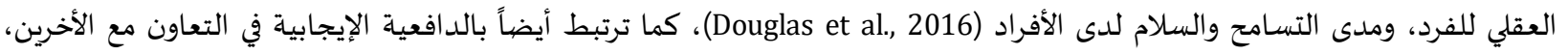

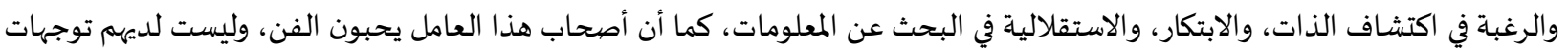

نحو السياسة. (Soldz \& Vaillant, 1999)

الانبساطية (Extraversion): يتمتع أصحاب سمة الانبساطية باتجاهات إيجابية نحو تقدير الإنجازات، والتفاعلات الاجتماعية، وتقدير

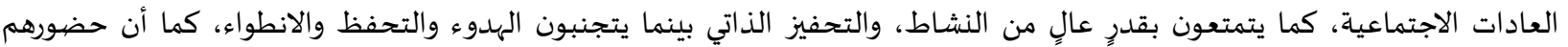

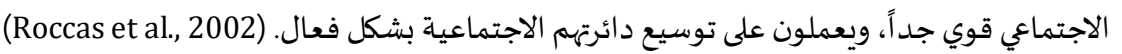

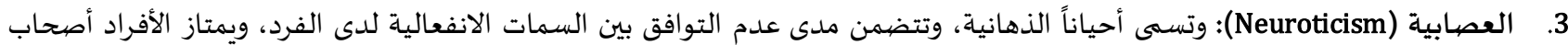

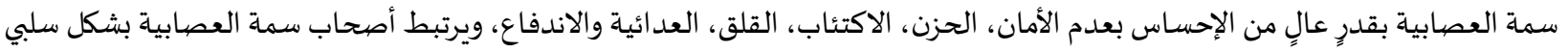

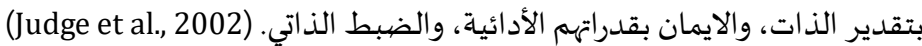

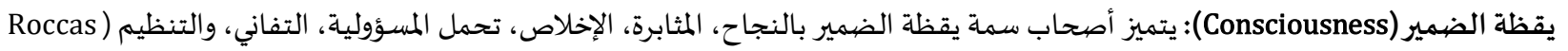
et al., 2002 ). كما أنهم يتصرفون بحكمة في المواقف الحياتية المختلفة، ويلتزمون بالواجبات وفقاً لما تمليه عليهم ضمائرهم، وقيمهم الأخلاقية.

(McCrae \& Costa, 1989)

المقبولية (Agreeableness): تعبر المقبولية لدى الأفراد عن السمات التي تركز على مراعاة رغبات الأخرين، واحترام مشاعرهم واستيعابهم، يميل

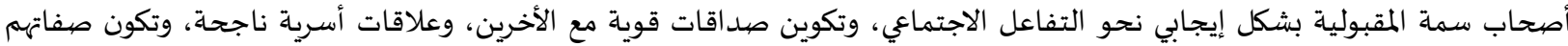

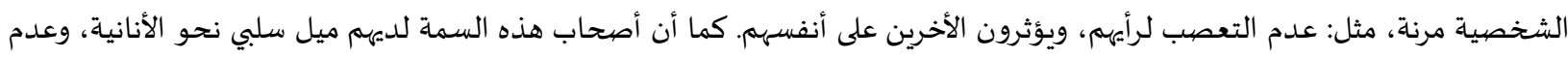

التسامح والعدوانية. (Ozer \& Benet, 2006) تتميز الشخصية البشرية بأن لها صفة التأثّر بما حولها، ومما لا شك فيه بأن تطوّر الحضـارة البشرية الحالية، وظهور شبكة المعلومات أعطى

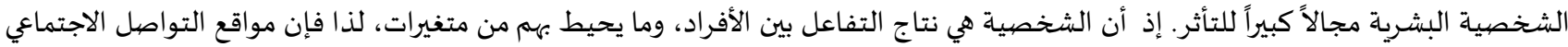

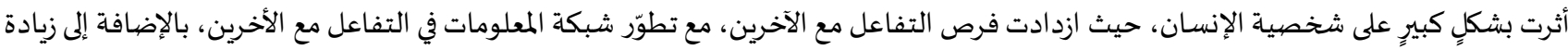

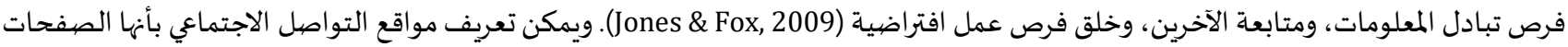
التي تتيح للمستخدم إنشاء ملف شخصي يحتوي العديد من الصفات التي يستطيع عرضها على الاخرين، والتعامل بهذه الشخصية وخية الافتراضية مع باقي الأشخاص (Jenkins, 2008).

يحتل الاتصال مكانة محورية في حياة البشر وأسباب رفاهيتهم، وقد أتاحت تكنولوجيا الإعلام والاتصال فرصاً جديدة في مجال التواصل

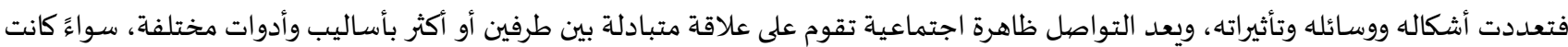

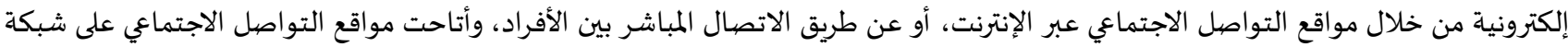

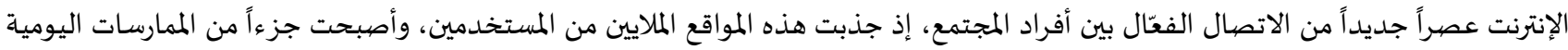

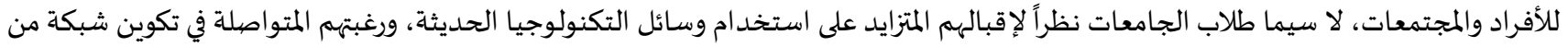
العلاقات مع أفراد من مجتمعاتٍ مختلفة. تشير الإحصاءات إلى أن واحداً من بين شخصئن مجاد من سكان العالم يستخدم مواقع التواصل الاجتماعي، إذ يبلغ عدد مستخدمي مواقع التواصل

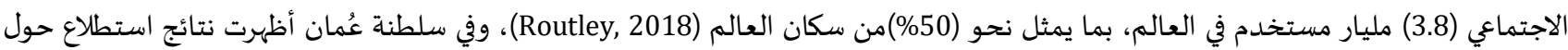

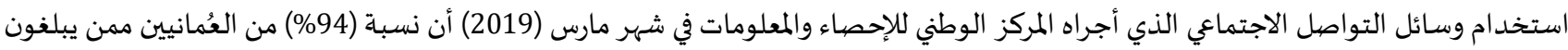

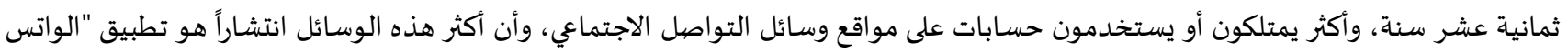

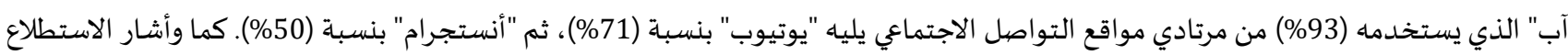

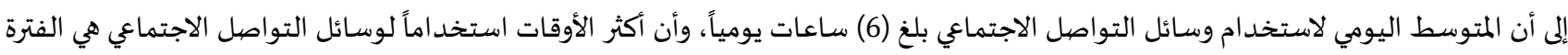

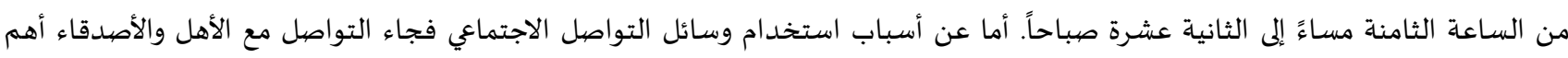

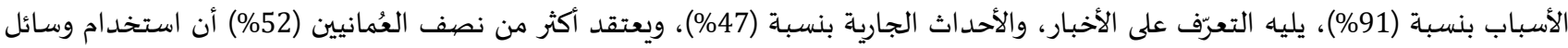

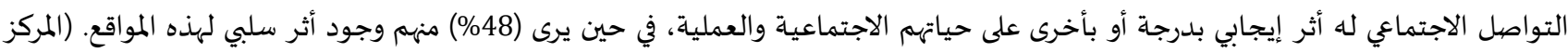
الوطني للإحصياء والمعلومات، 2019) 
الدراسات السابقة:

وبالنظر إلى العلاقة بين درجة استخدام مواقع التواصل الاجتماعي، وعوامل الشخصية الخمسة الكبرى، فقد أظهرت العديد من الدراسات بأن

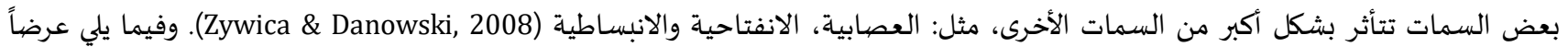

لمجموعة من هذه الدراسات:

أجرى كيركابرون وآخرون (Kircaburun et al., 2020) دراسـة هدفت إلى التحقق من مدى تأثير السمات الشخصية على دوافع استخدام مواقع

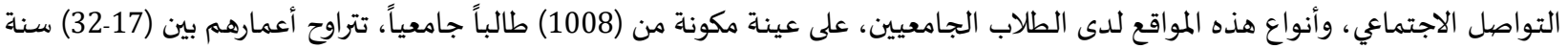
بمتوسط (20) سنة، وأشارت النتائج إلى أن هناك مجموعة من الدوافع المختلفة وراء استخدام مواقع التواصل الاجتماعي، وأن الطلاب يختلفون

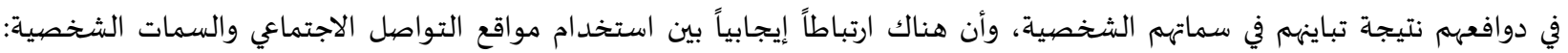

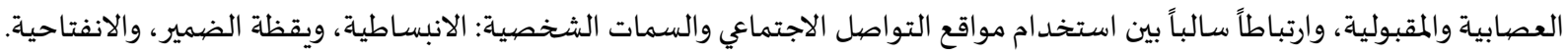
وقام و ايت وآخرون (Whaite et al., 2018) بدراسة هدفت إلى تقصي العلاقة بين خصائص الشخصية باستخدام نموذج سمات الشخصية الكبرى، واستخدام وسائل التواصل الاجتماعي، والعزلة الاجتماعياة، على عينة مكون من (1768) شاباً من الولايات المتحدة الأمريكية، تراوحت

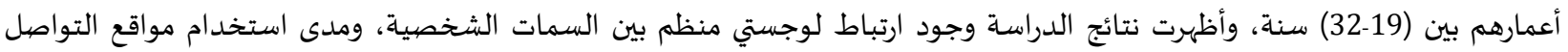
الاجتماعي، إذ كان هناك ارتباطاً عالياً بين درجة استخدات إندات مواقع التواصل الاجتماعي وسمة العصابية، في حين كان الارتباط منخفضياً لدى سمة الانبساطية، ومتوسطاً مع بقية السمات إنسات

وأجرت قدورة (2017) دراسة هدفت إلى الكشف عن العلاقة بين استخدام مواقع التواصل الاجتماعي وبعض سمات الشخصية والصحة

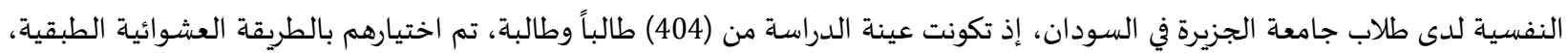

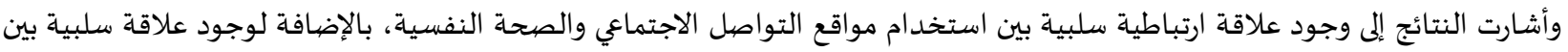

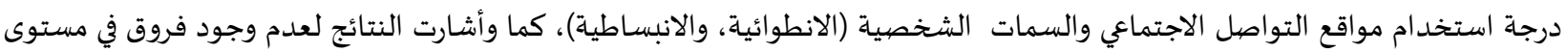

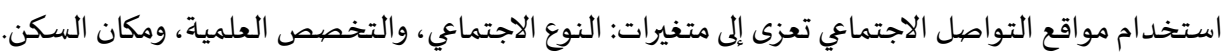

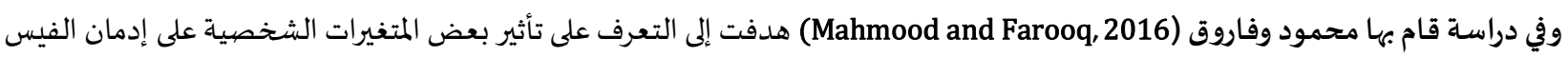

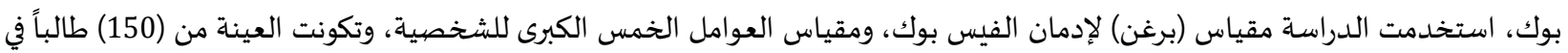

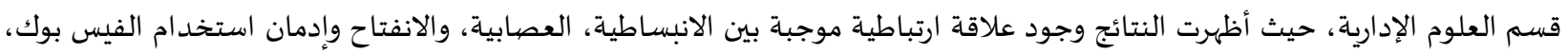
أيضاً اثبتت الدراسة وجود علاقة ارتباطية سالبة بين إدمان الفيس بوك والتحصيل التوديل الأكاديمي. أجرى الموافي وآخرون (2014) دراسة هدفت إلى التعرّف على استخدامات طلاب الجامعة لمواقع التواصل الاجتماعي وعلاقته بالعوامل الخمسـة

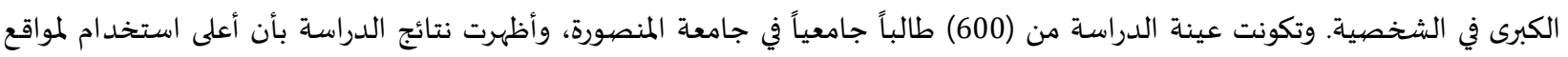
التواصل الاجتماعي كان لدى العصابيين، في حين كان أقل استخدام لدى سمة يقظة الضمير، وكانت درجة الاستخدام متوسطة ومتقاربة لدى لدئ السمات الشخصية الأخرى. وقامت كوريا وآخرون (Correa et al., 2013) بدراسـة هدفت إلى دراسـة العلاقة بين بعض سمات الشخصية الخمسة الكبرى واستخدام مواقع

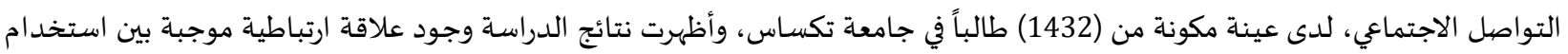

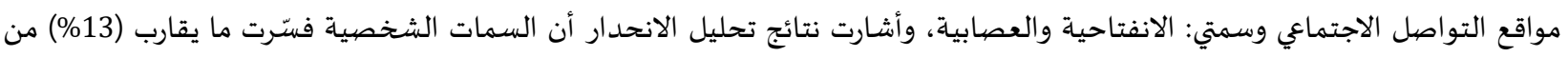
التباين في استخدام مواقع التواصل الاجتماعي، لهذا تعد السمات الشخصياة متنبئ جيد باستخدام مواقع التواصل الاجتماعي. وأخيراً أجرى هوجس وآخرون (Hughes et al., 2012) دراسة هدفت إلى مقارنة نوع موقع التواصل الاجتماعي (الفيسبوك، وتويتر) وفقاً للسمات

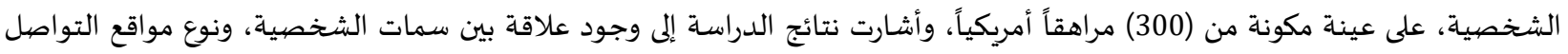

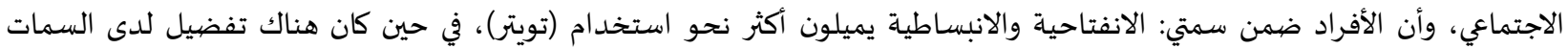

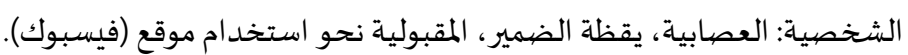

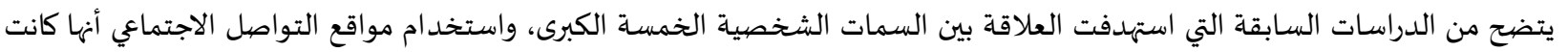

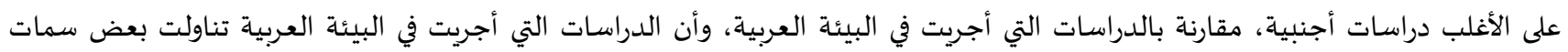

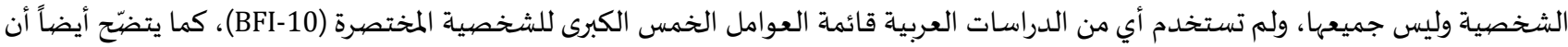

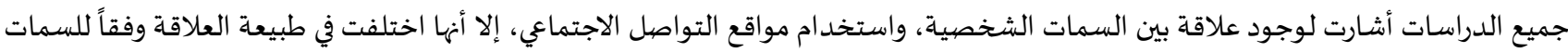
الشخصية الخمساة، وتأتي هذه الدراسة للتحقق من طبيعة العلاقة بين السمات الشخصية الخمسة الكبرى، واستخدام مواقع التواصل الاجتماعي لدى طلاب جامعة الشرقية في سلطنة عُمان. 
مشكلة الدراسـة وأسئلتها:

أصبحت مواقع التواصل الاجتماعي ظاهرة عالمية واسعة الانتشار، استطاعت أن تجعل الشباب عامة وطلاب الجامعات بصيفة خاصية يتعلقون

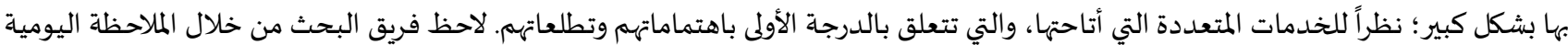
أن نسبة انتشار ظاهرة استخدام مواقع التواصل الاجتماعي تزداد يوماً بعد يوم بين طلاب الجامعة، وفي جميع مرافق الجامعة، وأحياناً أثناء

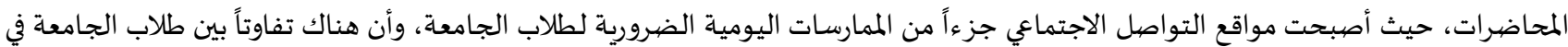
درجة استخد ام هذه المواقع، لذا فإن الكشف عن طبيعة العلاقة بين استخدام مواقع التواصل الاجتماعي، والسمات الشخصية، يؤدي إلى التعرّف

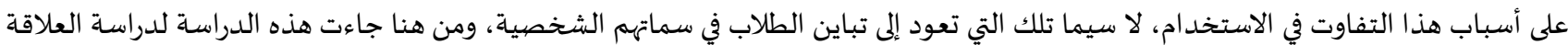
بين السمات الشخصية الخمسة الكبرى، واستخدام مواقع التواصل الاجتماعي لدى طلاب جامعة الشرقية في سلطنة عُمان، وتسعى الدراسـة إلى هُه الإجابة عن الأسئلة الآتية:

1. ما سمات الشخصية الخمس الكبرى الأكثر شيوعاً لدى طلاب جامعة الشرقية؟ الاهيه

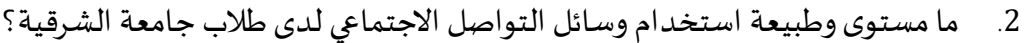
3. هل توجد علاقة ارتباطية ذات دلالة إحصائية بين العوامل الخمس الكبرى للشخصية واستخدام مواقع التواصل الاجتماعي ؟

أهمية الدراسـة:

• ب الأهمية النظرية:

تكتسب الدراسـة أهميتها من كونها تستهدف ظاهرة اجتماعية تتزايد باستمرار من يومٍ إلى آخر والمتمثلة في استخدام مواقع التواصل الاجتماعي بين

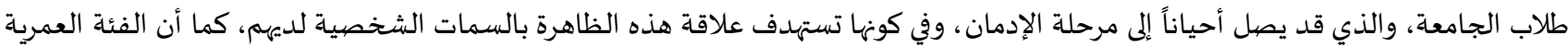
المستهدفة (طلاب الجامعات) هي من أهم فئات المجتمع، وأكثرها حيوية، وفي المقابل أكثرها استخداماً لمواقع التواصل الاجتهائمائي.

• الأهمية العملية:

1. توفير مقايس نفسية ذات خصائص جيدة؛ لقياس المتغيرات المستهدفة في الدراسة وهي: استخدام مواقع التواصل الاجتماعي، العوامل الخمس

الكبرى للشخصياة.

2. الكشف عن طبيعة العلاقة بين السمات الشخصية ودرجة استخدام مواقع التواصل الاجتماعي، وإمكانية التنبؤ بدرجة استخدام مواقع

$$
\text { التواصل الاجتماعي في ضوء السمات الشخصية. }
$$

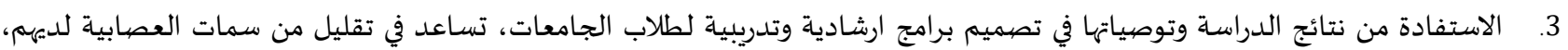

وتوعيتهم بالاستخدام الأمثل لمواقع التواصل الاجتماعي.

أهداف الدراسة:

تسعى الدراسـة إلى تحقيق الأهد اف الآتية:

1. معرفة السمات الشخصية الخمس الكبرى الأكثر شيوعاً لدى طلاب جامعة الشردية الشرقية.

2. تقصي درجة وطبيعة استخدام طلاب جامعة الشرقية لمواقع التواصل الاجتماعي.

3. الكشف عن العلاقة بين درجة استخدام مواقع التواصل الاجتماعي والسمات الشخصية.

4. الكشف عن مقدار التنبؤ بدرجة استخدام مواقع التواصل الاجتماعي في ضوء السمات السمات الشخصية.

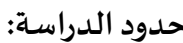

الحدود المكانية: جامعة الشرقية في سلطنة عُمان.

الحدود الزمانية: الفصل الدراسي الأول من العام الدراسي (2021/2020).

الحدود البشرية: طلاب جامعة الشرقية المسجلين خلال العام الدراسي (2021/2020).

الحدود الموضوعية: دراسة العلاقة بين السمات الشخصية الخمسة الكبرى، واستخدام مواقع التواصل الاجتماعي. 
تعريف المصطلحات:

• العوامل الخمس الكبرى للشخصية: هي خمسة عوامل أساسية لوصف الشخصية الإنسانية، يُمثل كل منها تجريداً لمجموعة من السمات المتناغمة، توصل إلهها العلماء والباحثون في ميدان الشخصية من خلانلان الأدلة العلمية للبحوث التجريبية، وهي: المقبولية، يقظة الضيمير، الانفتاحية، الانبساطية، العصابية (Mc care \& Costa, 1996).

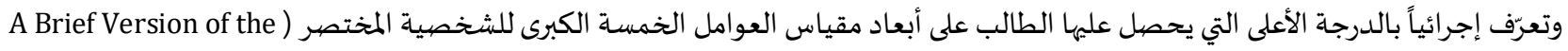
(Big Five Personality Inventory, BFI-10 من إعداد (Rammstedt \& John, 2007)

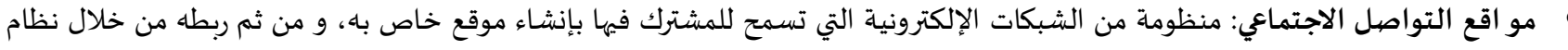

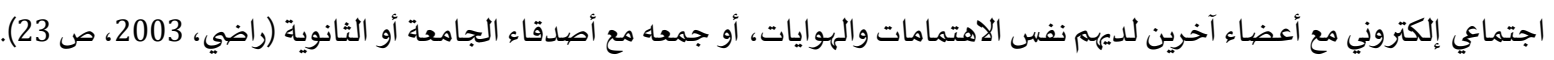
وتعرّف درجة استخدام مواقع التواصل الاجتماعي إجرائياً بأنها: الدرجة التي يحصيل عليها الطالب على على مقياس استخدام مواقع التواصل الاجتماعي المستخدم في الدراسـة.

إجراءات الدراسـة:

منهجية الدراسـة:

تمّ استخدام المنهج الوصفي الارتباطي في الدراسة؛ لوصف وتحليل وتفسير نتائج استجابات أفراد عينة الدراسـة، ودراسة العلاقة الارتباطية بين العوامل الخمس الكبرى للشخصية، ودرجة استخدام مواقع التواصل الاجتماعي.

مجتمع الدراسـة وعينتها:

يتكون مجتمع الدراسة من جميع طلاب جامعة الشرقية المسجلين خلال العام الدراسي (2021/2020)، والبالغ عددهم تقريباً (451) (452) طالباً

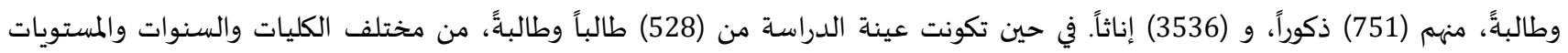
الدراسية، ويوضّح الجدول (1) توزيع أفراد ومجتمع عينة الدراسة.

\begin{tabular}{|c|c|c|c|c|}
\hline \multicolumn{5}{|c|}{ جدول (1): توزيع أفراد مجتمع وعينة الدراسة } \\
\hline النسبة المئوية & عدد أفراد & المدجدمع أفراد & 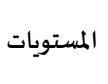 & 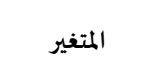 \\
\hline $10.1 \%$ & 76 & 751 & ذكور & \\
\hline $12.8 \%$ & 452 & 3536 & إناث & المقو الجنماتي \\
\hline $15.6 \%$ & 205 & 1313 & الأولى & \\
\hline $10.0 \%$ & 115 & 1148 & 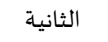 & \\
\hline $12.0 \%$ & 128 & 1070 & 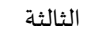 & 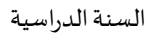 \\
\hline $10.3 \%$ & 42 & 406 & 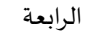 & \\
\hline $10.9 \%$ & 38 & 350 & 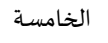 & \\
\hline $11.7 \%$ & 210 & 1801 & الآداب & \\
\hline $10.5 \%$ & 150 & 1428 & الإدارة & \\
\hline $13.6 \%$ & 51 & 376 & 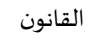 & 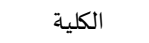 \\
\hline $16.3 \%$ & 46 & 282 & 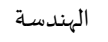 & \\
\hline $17.8 \%$ & 71 & 400 & العلوم & \\
\hline $12.3 \%$ & 528 & 4295 & & \\
\hline
\end{tabular}

أدوات الدراسة: أولاً: مقياس العوامل الخمس الدبها: التبرى للشخصية المختصر

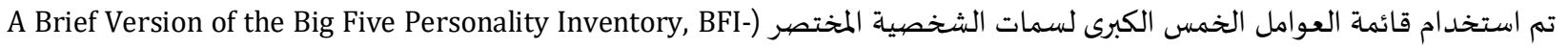
Rammstedt \& John, 2007)، ويتكون المقياس من (10) من إعدرات خماسية التدريج على مقياس ليكرت (1 غير موافق بشدة، 5 موافق بشدة)، تقيس خمس سمات للشخصية هي: المقبولية (Agreeableness)، يقظة الضمير (Consciousness)، الانفتاحية (Openness)، الانبساطية

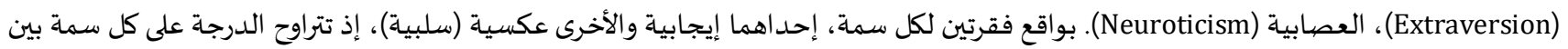
(10-2)، وليس للمقياس درجة كليّة. 
ثانياً: مقياس درجة استخدام مو اقع التواصل الاجتماعي

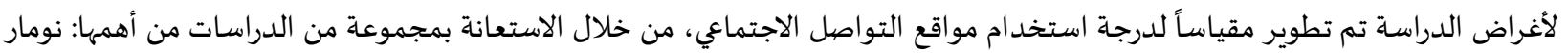

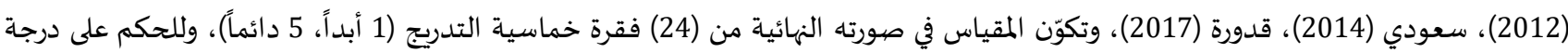

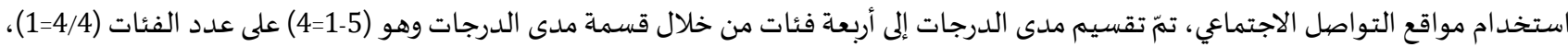

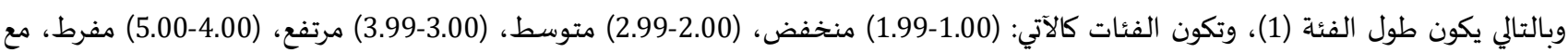
مراعاة عكس تدريج الفقرات السلبية. صددق أداتي الدراسـة: بعد إعداد أدوات الدراسة تمّ عرضها على مجموعة من المحكمين المختصين في علم النفس، القياس والتقويم، الإرشاد النفسي والتربوي، بلغ وذئ

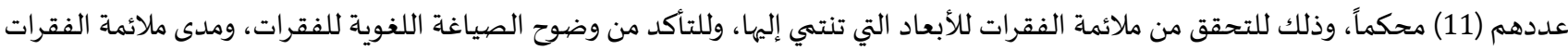
للبيئة العُمانية، إذ تم تعديل بعض الفقرات في ضوء توجيهات المحكمين؛ لتظهر المقاييس بالصورة النهائية الملائمة للتطبيق.

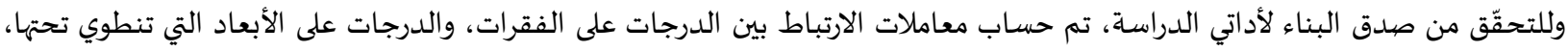
لمقياس سمات الشخصية، في حين تم حساب معاملات الارتباط بين الدرجات على الفقرات، والدرجات على كامل المقياس، لمقياس درجة استخدام مواقع التواصل الاجتماعي، ويوضّح الجدول (2) معاملات الارتباط بين الفقرات والأبعاد.

\begin{tabular}{|c|c|c|c|c|c|}
\hline الأارتباط مع & الفقرة & الارتباط مع الأداة & الفقرة & الارتباط مع & الفقرة \\
\hline \multicolumn{4}{|c|}{ درجة استخدام مواقع التواصل الاجتماعي } & \multicolumn{2}{|c|}{ العوامل الخمس الكبرى } \\
\hline $0.46^{* *}$ & 13 & $0.48^{* *}$ & 1 & $0.69^{* *}$ & 1 \\
\hline $0.45^{* *}$ & 14 & $0.34^{* *}$ & 2 & $0.73^{* *}$ & 2 \\
\hline $0.61^{* *}$ & 15 & $0.47^{* *}$ & 3 & $0.70^{* *}$ & 3 \\
\hline $0.37^{* *}$ & 16 & $0.49^{* *}$ & 4 & $0.78^{* *}$ & 4 \\
\hline $0.56^{* *}$ & 17 & $0.39^{* *}$ & 5 & $0.89^{* *}$ & 5 \\
\hline $0.51^{* *}$ & 18 & $0.42^{* *}$ & 6 & $0.71^{* *}$ & 6 \\
\hline $0.54^{* *}$ & 19 & $0.35^{* *}$ & 7 & $0.77^{* *}$ & 7 \\
\hline $0.60^{* *}$ & 20 & $0.64^{* *}$ & 8 & $0.78^{* *}$ & 8 \\
\hline $0.65^{* *}$ & 21 & $0.49^{* *}$ & 9 & $0.84^{* *}$ & 9 \\
\hline $0.53^{* *}$ & 22 & $0.43^{* *}$ & 10 & $0.67^{* *}$ & 10 \\
\hline $0.36^{* *}$ & 23 & $0.52^{* *}$ & 11 & & \\
\hline $0.38^{* *}$ & 24 & $0.39^{* *}$ & 12 & & \\
\hline
\end{tabular}

يتضح من الجدول (2) أن معاملات الارتباط بين الفقرات والأبعاد لمقياس العوامل الخمس الكبرى للشخصية تراوحت بين (0.67-0.89)، في حين

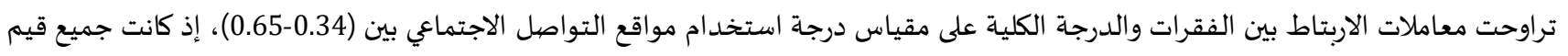

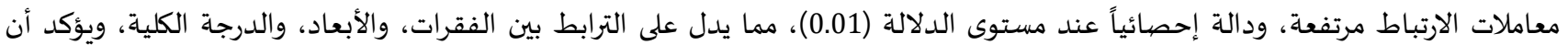
المقياسين يتمتعا بقدٍٍ مرتفع من صدق البناء. ثبات أداتي الدراسة: تم التحقق من ثبات مقياس العوامل الخمس الكبرى للشخصية باستخدام طريقة ثبات الاستقرار، من خلال حساب معامل ارتباط بيرسون بين

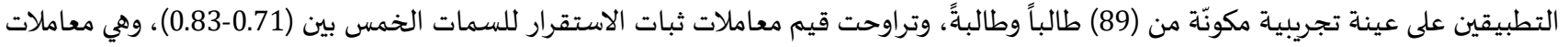

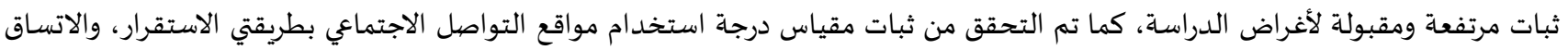

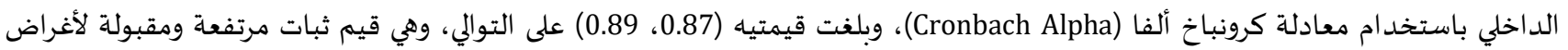
الدراسة. 
نتائج الدراسة ومناقشتها:

أولاً: النتائج المتعلقة بالسؤال الأول ومناقشتها

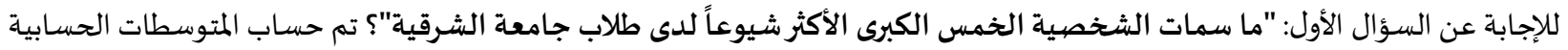

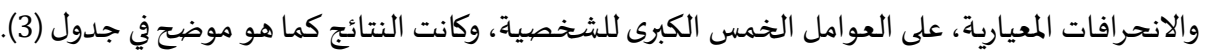

\begin{tabular}{|c|c|c|c|c|}
\hline المستوى & 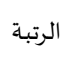 & الانحراف المعياري & المتوسط الحسابي & البُعد \\
\hline مرتفع & 1 & 1.39 & 8.19 & المقبولية \\
\hline مرتفع & 3 & 1.54 & 7.49 & يقظة الضمير \\
\hline مرتفع & 2 & 1.57 & 7.61 & الانفتاحية \\
\hline متوسط & 5 & 1.28 & 5.98 & الانبساطية \\
\hline متوسط & 4 & 1.79 & 6.05 & العصابية \\
\hline
\end{tabular}

يلاحظ من الجدول (3) أن سمة الشخصية الأكثر شيوعاً لدى أفراد عينة الدراسة هي سمة المقبولية، بمتوسط حسابي (81. (8.19)، تلهيا سمة

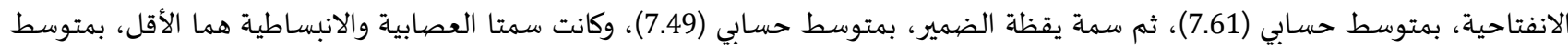

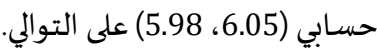

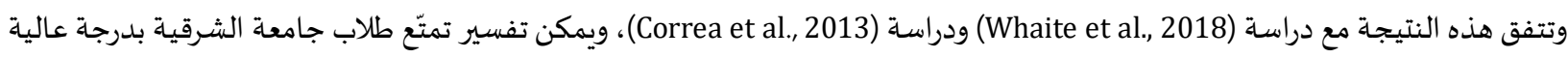

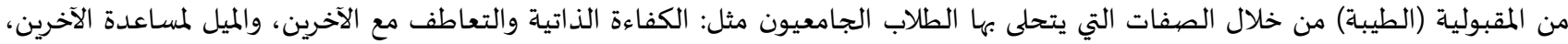

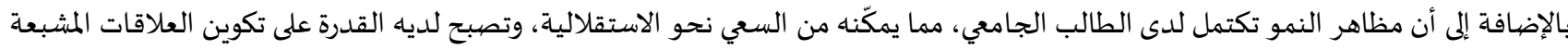

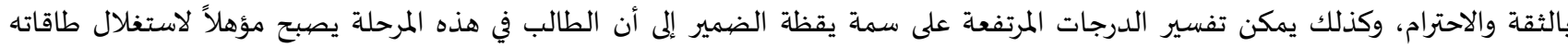

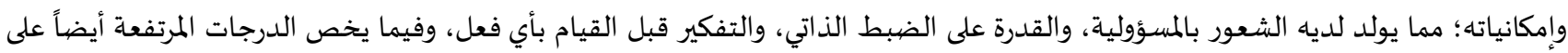

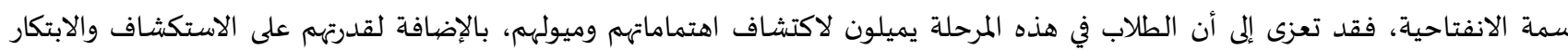

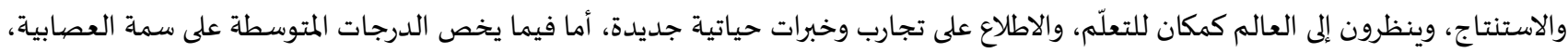

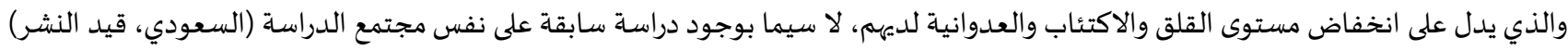

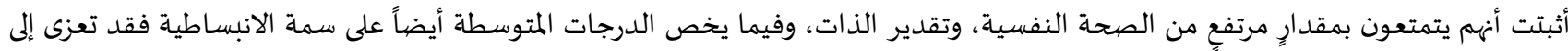

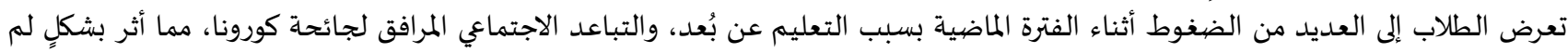

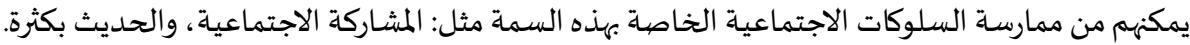
ثانياً: النتائج المتعلقة بالسؤال الثاني ومناقشتها

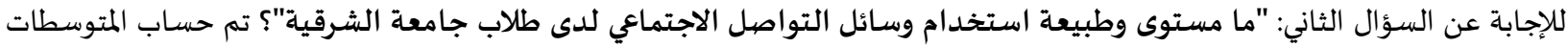

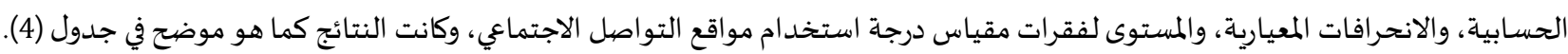

\begin{tabular}{|c|c|c|c|}
\hline 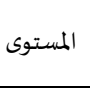 & المعياري & الوسط الحسابي & 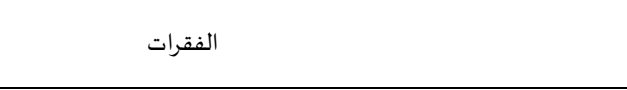 \\
\hline 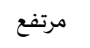 & 1.11 & 3.12 & استخدامي لمواقع التواصل الاجتماعي يخلصني من الشعور بالوحدة \\
\hline 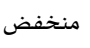 & 0.92 & 1.65 & أشاهد أفلام العنف والقتال على مواقع التواصل الاجتماعي \\
\hline 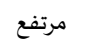 & 1.17 & 3.25 & أشعر بأن الحياة بدون مواقع التواصل الاجتماعي مملة \\
\hline 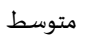 & 1.13 & 2.16 & استخدامي لمواقع التواصل الاجتماعي أبعدني عن زملائي وأسرتي \\
\hline 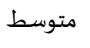 & 1.18 & 2.85 & استخدامي لمواقع التواصل الاجتماعي يجعلني أكثر ثقة بنفسي \\
\hline 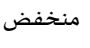 & 0.69 & 1.43 & أتعرض للخداع من قبل آخرين عبر مواقع التواصل الاجتماعي \\
\hline 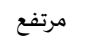 & 0.86 & 3.93 & استخدامي لمواقع التواصل الاجتماعي يزيد من حصيلتي المعرفية \\
\hline متوسط & 1.26 & 2.56 & يشكو أفراد أسرتي من كثرة استخدامي لمواقع التواصل الاجتماعي \\
\hline 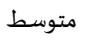 & 1.10 & 2.01 & أفضل التواصل عبر مواقع التواصل الاجتماعي عن التواصل مع الأسرة \\
\hline متوسط & 1.21 & 2.03 & تعجبني العلاقات التي تتجاوز بعض القيود عبر مواقع التواصل الاجتماعي \\
\hline 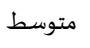 & 1.13 & 2.65 & أستخدم مواقع التواصل الاجتماعي أثناء المحاضرات \\
\hline مرتفع & 1.21 & 3.30 & أعبّر عن رأيي بحرية عبر مواقع التواصل الاجتماعي \\
\hline
\end{tabular}




\begin{tabular}{|c|c|c|c|}
\hline متوسط & 1.04 & 2.74 & التواصل عبر مواقع التواصل الاجتماعي يساعدني في حل مشكلاتي \\
\hline 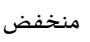 & 0.72 & 1.31 & مواقع التواصل الاجتماعي تتسبب في غيابي المتكرر عن المحاضرات \\
\hline 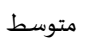 & 1.20 & 2.83 & عندما أغلق أحد مواقع التواصل الاجتماعي أجد رغبة قوية في العودة إليه \\
\hline 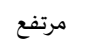 & 1.29 & 3.21 & أشعر بالندم بعد قضاء وقت طويل في استخدام أحد مواقع التواصل الاجتماعي \\
\hline 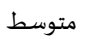 & 1.14 & 2.15 & استخدامي لمواقع التواصل الاجتماعي يصيبني بالانطواء والانعزال \\
\hline 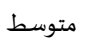 & 1.32 & 2.65 & استخدامي لمواقع التواصل الاجتماعي يعوضني عن غياب الأصدقاء \\
\hline 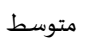 & 1.21 & 2.23 & استخدامي لمواقع التواصل الاجتماعي يؤثر سلباً في تحصيلي الدراسي \\
\hline 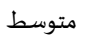 & 1.36 & 2.97 & أشعر بأن استخدامي لمواقع التواصل الاجتماعي أثّر على نظام نومي \\
\hline 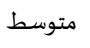 & 1.26 & 2.45 & أعاني من آلام في يدي ورقبتي من متابعة مواقح التواصل الاجتماعي \\
\hline 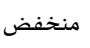 & 1.10 & 1.79 & تلهيني متابعة مواقع التواصل الاجتماعي عن الأكل \\
\hline 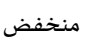 & 0.79 & 1.34 & أشاهد المقاطع الإباحية على مواقع التواصل الاجتماعي \\
\hline 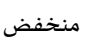 & 0.68 & 1.32 & أتعرض للتنمر من آخرين على مواقع التواصل الاجتماعي \\
\hline متوسط & 0.51 & 2.41 & الكلي \\
\hline
\end{tabular}

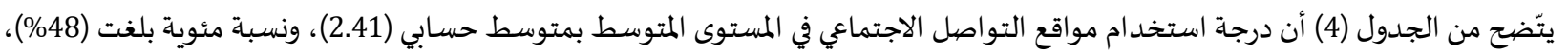

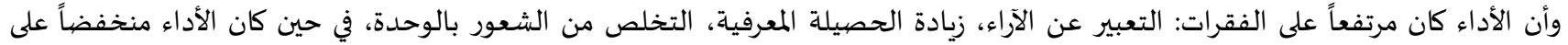

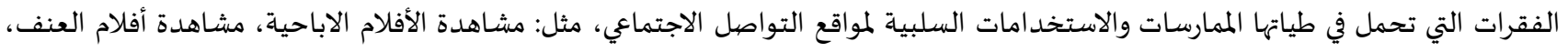

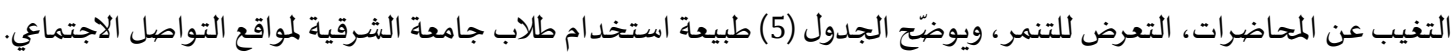

\begin{tabular}{|c|c|c|c|c|c|}
\hline النسب المئوية & العدد & الفئات & النسب المئوية & العدد & الفئات \\
\hline \multicolumn{3}{|c|}{ ساعات الاستخدام } & \multicolumn{3}{|c|}{ موقع التواصل } \\
\hline $10.0 \%$ & 53 & أقل من ساعتين & $21.6 \%$ & 114 & تويتر \\
\hline $24.4 \%$ & 129 & 4-2 ساعات & $2.5 \%$ & 13 & فيسبوك \\
\hline $34.7 \%$ & 183 & 6-6 ساعات & $67.8 \%$ & 358 & واتس اب \\
\hline $30.9 \%$ & 163 & أكثر من 6 ساعات & $29.2 \%$ & 154 & يوتيوب \\
\hline \multicolumn{3}{|c|}{ وقت الاستخدام } & $36.2 \%$ & 191 & سناب شات \\
\hline $7.0 \%$ & 37 & 6 صباحاً -2مساءً & $60.2 \%$ & 318 & انستجرام \\
\hline $37.1 \%$ & 196 & 2 مساءً 10 مساءً & \multicolumn{3}{|c|}{ غرض الاستخدام } \\
\hline $13.4 \%$ & 71 & 10 صباحاً -6 صباحاً & $62.1 \%$ & 328 & علمية وثقافية \\
\hline $42.4 \%$ & 224 & في أي وقت & $6.8 \%$ & 36 & سياسية \\
\hline \multicolumn{3}{|c|}{ درجة الاستخدام } & $22.7 \%$ & 120 & تجارية \\
\hline $17.8 \%$ & 94 & منخفض & $79.5 \%$ & 420 & اجتماعية \\
\hline $65.3 \%$ & 345 & متوسط & $70.6 \%$ & 373 & ترفهية \\
\hline $11.6 \%$ & 61 & مرتفع & $9.1 \%$ & 48 & رياضية \\
\hline $5.3 \%$ & 28 & مفرط & $2.1 \%$ & 11 & أخرى \\
\hline
\end{tabular}

ويشير الجدول (5) إلى أن أكثر مواقع التواصل الاجتماعي استخداماً من قبل الطلاب هو (واتس اب) بنسبة (68\%) يليه (انستجرام) بنسبة

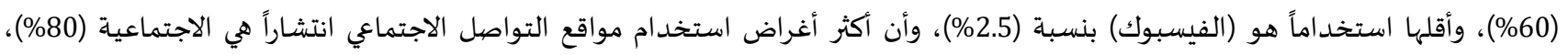

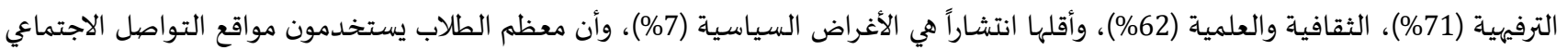
لأكثر من ساعتين يومياً، وأن (42\%) يستخدمونها في أي وقت من اليوم، و(37) (62) يستخدمونها من الساعة الثانية مساءً لغاية الساعة العاشرة مساءً،

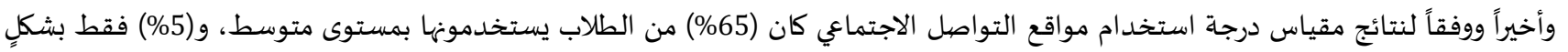

وتدل هذه النتيجة على أن الطلاب يستخدمون مواقع التواصل الاجتماعي ضمن الحد المعقول دون إفراط، إذ بلغ نسبة الطلاب الذين كان لديهم

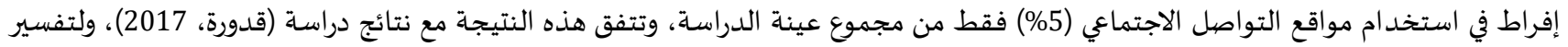

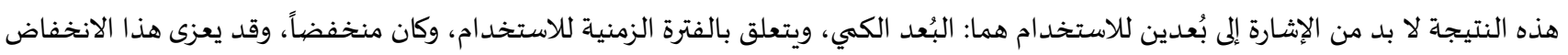
إلى أن أفراد عينة الدراسة هم من الطلاب الجامعيين، إذ أن الوقت المخصص لدئه الديهم لاستخدام هذه المواقع يكون أقل من الفئات الأخرى ممن هم في 
مستواهم العمري؛ بسبب انشغالهم بالأنشطة والمهام الدراسية، لا سيما في ظل التعليم عن بُعد، والذي يتطلب عادةً وقت أطول للدراسة من التعليم الوجاهي.

أما الجانب الآخر وهو البُعد النوعي المتعلق بطبيعة الاستخدام، والذي يفسّر أيضاً في ضوء طبيعة عينة الدراسة (طلاب الجامعة)، حيث أظهر نسبة كبيرة من الطلاب أن استخدامهم كان للأغراض العلمية والثقافية، وكذلك الاجتماعية للتواصل مع الأصدقاء والأقارب، أي أن معظم

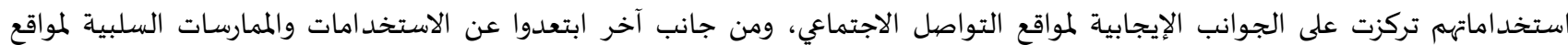

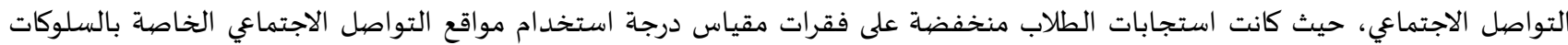

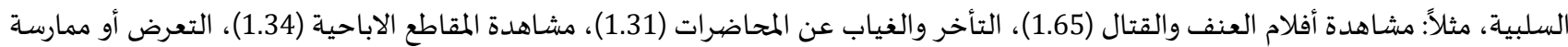

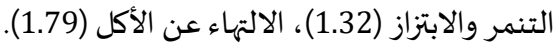
ثالثاً: النتائج المتعلقة بالسؤال الثالثراز (1)، ومناقشتهاء للإجابة عن السؤال الثالث: "هل توجد علاقة ارتباطية ذات دلالة إحصائية بين العوامل الخمس الكبرى للشخصية واستخدام مو اقع التواصل الاجتماعي "؟ تم حسـاب معاملات الارتباط (بيرسون) بين الدرجات على مقياس استخدام مواقع التواصل الاجتماعي، والدرجات الفرعية لكل

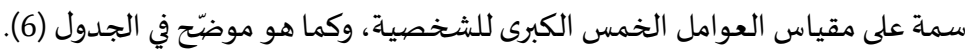
جدول (6): معاملات ارتباط بيرسون بين السمات الشخصية ودرجة استخدام مو اقع التواصل الاجتماعي

\begin{tabular}{|c|c|c|c|c|c|c|}
\hline العصابية & الانبساطية & الانفتاحية & الضمير & المقبولية & مواقع & المقياس \\
\hline $0.27^{* *}$ & -0.04 & 0.05 & $-0.51^{* *}$ & $-0.31^{* *}$ & 1 & مواقع التواصل \\
\hline$-0.25^{* *}$ & 0.06 & $0.14^{* *}$ & $0.40^{* *}$ & 1 & & المقبولية \\
\hline$-0.35^{* *}$ & $0.10^{*}$ & $0.12^{*}$ & 1 & & & يقظة الضمير \\
\hline$-0.15^{* *}$ & 0.04 & 1 & & & & الانفتاحية \\
\hline$-0.13^{* *}$ & 1 & & & & & الانبساطية \\
\hline 1 & & & & & & العصابية \\
\hline
\end{tabular}

(0.01) معامل ارتباط دال إحصائياً عند مستوى دلالة (0.05).

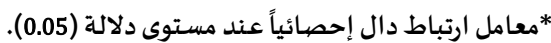

ويتضح من الجدول (6) وجود علاقة ارتباطية سلبية ودالة إحصائياً بين درجة استخدام مواقع التواصل الاجتماعي، والسمات الشخصية:

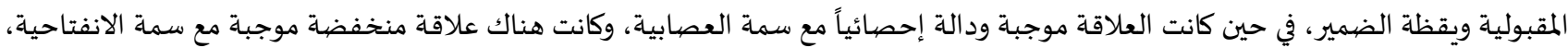
وعلاقة منخفضاة سالبة مع سمة الانبساطية. وفيما يخص الارتباطات بين السمات الشخصية فقد كان هناك معاملات ارتباط سالبة ودالة إحصائياً

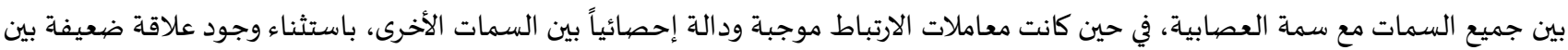
سمتي الانفتاحية ويقظة الضمير مع سمة الانبساطية. كما تم استخدام تحليل الانحدار الخطي المتعدد المعياري (Standard Multiple Linear Regression) للتنبؤ بمتغير درجة استخدام مواقع التواصل الاجتماعي من خلال متغير سمة الشخصية، إذ تم بداية التحقق من أهم شروط هذا التحليل وهي: التوزيع الطبيعي للقيم المعيارية للبواقي، حيث بلغت قيمة مستوى الدلالة لاختبار كولموغروف-سميرنوف (Kolmogorov-Smirnov) (0.25) وبالتالي فإن البواقي تتبع التوزيع الطبيعي، ويوضيّح الجدول (7) نتائج تحليل التباين الأحادي، ومعامل الارتباط المتعدد؛ للتحقق من دلالة نموذج التنبؤ، فيما يوضّح الجدول (8) نتائج تحليل الانحدار

المتعدد المعياري.

جدول (7): نتائج تحليل التباين الأحادي ومعامل الارتباط المتعدد للتحقق من دلالة نموذج التنبؤ

\begin{tabular}{|c|c|c|c|c|c|}
\hline الدلالة & قيمة F F & متوسط المربعات & درجة الحرية & مجموع المربعات & المصدر \\
\hline \multirow[t]{3}{*}{0.00} & 37.07 & 4153.90 & 5 & 20769.50 & النموذج \\
\hline & & 112.06 & 522 & 58497.47 & الخطأ \\
\hline & & & 527 & 79266.97 & المجمموع المعدّل \\
\hline 0.28 & \multicolumn{2}{|c|}{$\mathrm{R}^{2}$} & \multicolumn{2}{|c|}{57.92} & متوسط المتغير التابع \\
\hline 0.27 & \multicolumn{2}{|c|}{ المعدّل R2 } & \multicolumn{2}{|c|}{0.53} & معامل الارتباط المتعدد R \\
\hline
\end{tabular}


يلاحظ من الجدول (7) وجود دلالة احصائية للنموذج المستخدم للتنبؤ بدرجة استخدام مواقع التواصل الاجتماعي، وبالتالي وجود فروق ذات

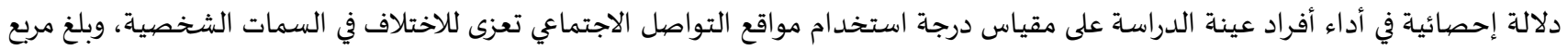

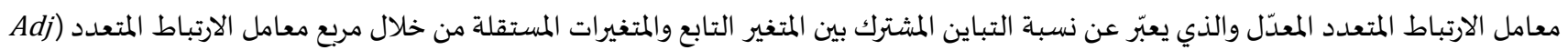

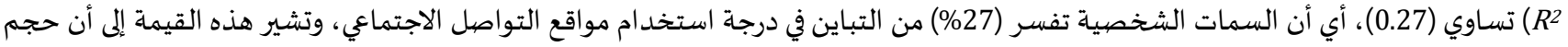
التأثير (Effect Size) مرتفعاً، وفقاً لما أشار إليه (Cohen, 1992) حيث يعتبر حجم التأثير قليلاً إذا كان بين (U) (0.02-0.12)، ومتوسطاً إذا كان بين (0.130.25)، ومرتفعاً إذا كان أكبر من (0.26).

جدول (8): نتائج تحليل الانحدار المتعدد المعياري

\begin{tabular}{|c|c|c|c|c|c|}
\hline دلالةت & قيمة ت & الخطأ المعياري & معامل الانحدار & معامل الانحدارغير & المتغير \\
\hline 0.000 & 16.88 & 5.11 & & 86.21 & ثابت الانحدار \\
\hline 0.001 & -3.41 & 0.73 & -0.14 & -2.51 & المقبولية \\
\hline 0.000 & -9.87 & 0.68 & -0.42 & -6.72 & يقظة الضيمير \\
\hline 0.001 & 3.33 & 0.60 & 0.13 & 1.99 & الانفتاحية \\
\hline 0.014 & 1.82 & 0.56 & 0.11 & 1.46 & العصابية \\
\hline 0.037 & -1.48 & 0.72 & -0.09 & -1.62 & الانبساطية \\
\hline
\end{tabular}

يتضع من الجدول (8) أن جميع السمات الشخصية كان لها قدرةً على التنبؤ بدرجة استخدام مواقع التواصل الاجتماعي، إذ كانت مستوى دلالة جميع قيم (ت) أقل من (0.05)، وكانت السمات: الانفتاحية، والعصابية تتنباً بشكل إيجابي بدرجة استخدام مواقع التواصل الاجتماعي، في حين تنبأت السمات: المقبولية، يقظة الضمير، الانبساطية بشكل سلبي بدرجة استخدام مواقع التواصل الاجتماعي، أي أن درجة استخدام مواقع التواصل

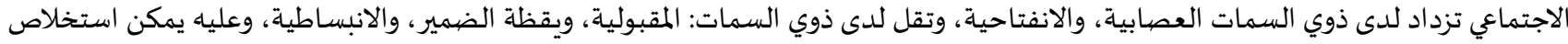

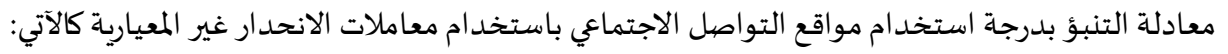
درجة استخدام مو اقع التواصل الاجتماعي = 86.21 - (2.51) المقبولية - (6.72) يقظة الضيمير + (1.99) الانفتاحية + (1.46) العصبابية (1.62) الانبساطية

وتتفق هذه النتيجة مع العديد من الدراسـات السـابقة مثل دراسة (قدورة، 2017)، ودراسة (Correa et al., 2013)، ودراسة (Hughes et 2012)

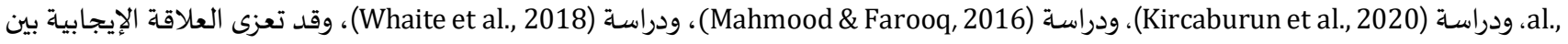
سمة العصابية واستخدام مواقع التواصل الاجتماعي إلى أن الأفراد العصابيين -والذين يتصفون بالقلق، والاكتئاب، وانخفاض تقدير الذات- يميلون أكثر لاستخدام مواقع التواصل الاجتماعي نتيجة سوء التكيّف مع البيئة المحيطة، ومع أفراد المجتمع، إذ تفضّل هذه الفئة التفاعل مع المجتمعات

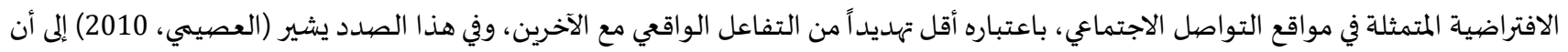
الأفراد يستخدمون الإنترنت من أجل التواصل الاجتماعي، والحاجة إلى التنشئة الاجتماعية، ويبحثون عن الأشخاص المشاهين لهم ليتواصلوا معهم،

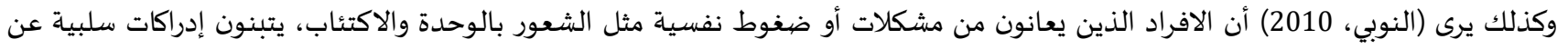

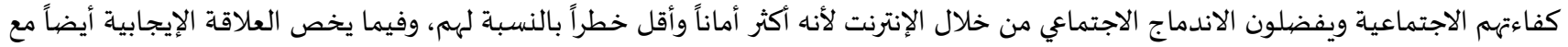

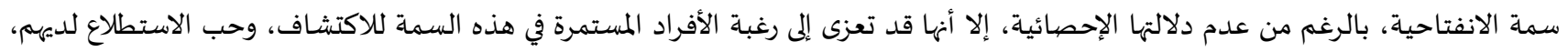

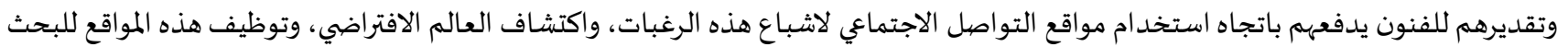
عن اهتماماتهم الفنية المختلفة. أما بخصوص العلاقة السلبية بين استخدام مواقع التواصل الاجتماعي والسمات الشخصية: المقبولية، ويقظة الضمير، والانبساطية، فيمكن تفسيرها من خلال الخصائص التي يتمتع بها الأفراد ضمن هذه السمات والمتمثلة في القدرة على الحفاظ على العلاقات مع الآخرين، والكفاءة الذاتية،

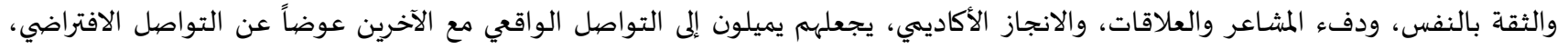
ويكرّسون معظم أوقاتهم للانجاز الأكاديمي وأداء مهامهه وأنشطتهم الدراسياة، بدلاً من قضاء أوقات طويلة على مواقع التواصل الاجتماعي. 


$$
\text { في ضوء النتائج التي توصلت إلهها الدراسة، تم اقتراح مجموعة من التوصيات على النحو الآتي: }
$$

تقديم برامج إرشادية، ودورات تدرببية لطلاب الجامعات تهدف إلى: التوعية بالاستخدام الأمثل لمواقع التواصل الاجتماعي، والتوعية بالآثار السلبية للافراط في استخدام هذه المواقع، تعزيز التواصل الواقعي، وتنمية المهارات الحياتية المختلفة لديهم، المسـاعدة على التخلص من

تم إجراء هذا البحث بتمويل من وزارة التعليم العالي والبحث والابتكار في سلطنة عمان، في إطار برنامج التمويل الجماعي. بموجب اتفاقية رقم

1. راضي، زاهر (2003). استخدام مواقع التواصل الاجتماعي في العالم العربي، مجلة التربية: جامعة عمان الأهلية. 1(15): 23-41.

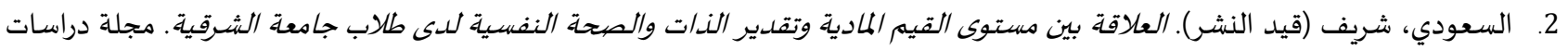

$$
\text { نفسية وتربوية: جامعة قاصهدي مرباح ورقلة. }
$$

3. سعودي، عبد الكريم (2014). إدمان الفيس بوك وعلاقتها بالتوافق الأسري للطالب الجامعي، دراسة على عينة من جامعة بشار. دراسات نفسية

$$
\text { وتربوية: 19(13): } 19 \text { (13) }
$$

4. العصيمي، سلطان (2010). إدمان الإنترنت وعلاقتاه بالتوافق النفسي الاجتماعي للدى طلاب الممحلة الثانوية بمدينة الرياض، [رسالة ماجستير

$$
\text { غير منشورة]. جامعة نايف العربية للعلوم الأمنية. السعودية. }
$$

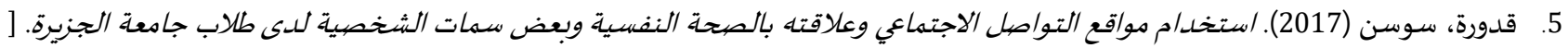

رسالة دكتوراه غير منشورة]. جامعة الخرطوم. السودان.

6. المركز الوطني للإحصاء والمعلومات (2019). استطاعلاع الرأي حول وسائل التواصل الاجتماعي في سلطنة عُمانمان، متوفر عبر الرابط: https://www.ncsi.gov.om/Pages/NCSI.aspx

7. الموافي، فؤاد ووحيش، أحمد وزيدان، عصام ومحمد، مروة (2014). استخدامات الشباب لمواقع التواصل الاجتماعي وعلاقته بالعوامل الخمسة

الكبوي في الشخصية لدي طلاب الجامعة (دراسة وصفية تحليلية لمستخدمي مواقع التواصل الاجتماعي). مجلة بحوث التهون التربية النوعية: 8(34):

.138-104

8. النوبي، محمد علي (2010). إدمان الإنترنت في عصر العولمة. دار صفاء. عمّان.

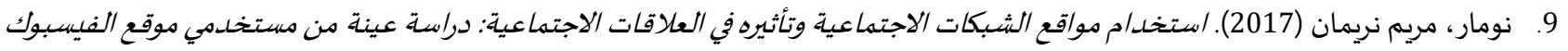

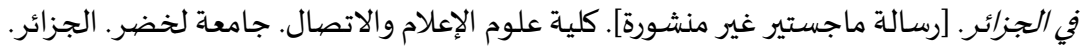

ثانياً: المراجع الأجنبية:

1. Cohen, J. (1992). A power primer. Psychological Bulletin, 112: 155-159.

2. Correa, T., Bachmann, I., Hinsley, W., \& De Zúñiga, G. (2013). Personality and social media use. In Organizations and social networking: Utilizing social media to engage consumers, IGI Global (41-61).

3. Costa, P., \& McCrae, R. (1985). The NEO Personality Inventory manual. Odessa, FL: Psychological Assessment Resources.

4. Douglas, E., Bore, M., \& Munro, D. (2016). Openness and intellect: An analysis of the motivational constructs underlying two aspects of personality. Personality and Individual Differences, 99(1): 242-253, https://doi.org/10.1016/j.paid.2016.05.030.

5. Eysenck, J. (2013). The Structure of Human Personality. New York: Routledge.

6. Hughes, J., Rowe, M., Batey, M., \& Lee, A. (2012). A tale of two sites: Twitter vs. Facebook and the personality predictors of social media usage. Computers in human behavior, 28(2): 561-569, https://doi.org/10.1016/j.chb.2011.11.001. 
7. Jenkins, H, (2008). Convergence culture : where Old and New Media Collide, NYU press, London.

8. Jones, S., \& Fox, S. (2009). Generations online in 2009 (pp. 1-9). Washington, DC: Pew Internet \& American Life Project.

9. Judge, A., Erez, A., Bono, E., \& Thoresen, J. (2002). Are measures of self-esteem, neuroticism, locus of control, and generalized self-efficacy indicators of a common core construct? Journal of Personality and Social Psychology, 83(3): 693710, https://doi.org/10.1037/0022-3514.83.3.693.

10. Kircaburun, K., Alhabash, S., Tosuntaş, B., \& Griffiths, D. (2020). Uses and gratifications of problematic social media use among university students: A simultaneous examination of the Big Five of personality traits, social media platforms, and social media use motives. International Journal of Mental Health and Addiction, 18(3): 525-547, https://doi.org/10.1007/s11469-018-9940-6.

11. Mahmood, Sh. \& Farooq, U. (2016). Facebook Addiction: A Study of Big-Five Factors and Academic Performance amongst Students of IUB. Global Journal of Management and Business Research: E Marketing, 14(5): 55-71.

12. Mc Crae, R., \& Costa, P. (1989). Reinterpreting the Myers-Briggs Type Indicator From the Perspective of the Five-Factor Model of Personality. Journal of Personality, 57(1): 17- 40, https://doi.org/10.1111/j.1467-6494.1989.tb00759.x.

13. McCrae, R., \& Costa, P. (1996). Toward a new generation of personality Theories: theoretical contexts for the five-factor model, in Wiggins, J.S. (Ed), The five-factor Model of Personality: Theoretical Perspectives, Guilford, New York, NY, 51-87.

14. Ozer, J., \& Benet-Martinez, V. (2006). Personality and the prediction of consequential outcomes. Annual Review of Psychology, 57(1): 401-421, https://doi.org/10.1146/annurev.psych.57.102904.190127.

15. Rammstedt, B. \& John, O. P. (2007). Measuring personality in one minute or less: A 10-item short version of the Big Five Inventory in English and German. Journal of Research in Personality, 41(1): 203-212, https://doi.org/10.1016/j.jrp.2006.02.001.

16. Roccas, S., Sagiv, L., Schwartz, H., \& Knafo, A. (2002). The Big Five personality factors and personal values. Personality and Social Psychology, 28(6): 789-801, https://doi.org/10.1177/0146167202289008.

17. Rosellini, A., \& Brown, T. (2011). The NEO FiveFactor Inventory: Latent Structure and Relationships with Dimensions of anxiety and Depressive Disorders in Large Clinical Sample. Assessment, 18(1): 27- 38, https://doi.org/10.1177/1073191110382848.

18. Routley, N. (2018). Visualizing the Social Media Universe in 2018, Online available from: https://www.visualcapitalist.com/social-media-universe/.

19. Ryckman, R. (2008). Theories of Personality. Belmont: Thompson Wadsworth. Salama-Younes, M. (2011). Positive mental health, subjective vitality and satisfaction with life for French physical.

20. Santrock, J.(2011). Educational Psychology. 5th ed, New York, Mc Graw Hill

21. Saucier, G. (2002). Orthogonal Markers For Orthogonal Factors: The Case of the Big Five. Journal of Research in Personality, 36(1): 1- 31, https://doi.org/10.1006/jrpe.2001.2335.

22. Soldz, S., \& Vaillant, E. (1999). The Big Five personality traits and the life course: A 45-year longitudinal study. Journal of Research in Personality, 33(1): 208-232, https://doi.org/10.1006/jrpe.1999.2243.

23. Whaite, O., Shensa, A., Sidani, E., Colditz, B., \& Primack, A. (2018). Social media use, personality characteristics, and social isolation among young adults in the United States. Personality and Individual Differences, 124(1): 45-50, https://doi.org/10.1016/j.paid.2017.10.030.

24. Zywica, J., \& Danowski, J. (2008). The faces of Facebookers: Investigating social enhancement and social compensation hypotheses; predicting Facebook ${ }^{\mathrm{TM}}$ and offline popularity from sociability and self-esteem, and mapping the meanings of popularity with semantic networks. Journal of Computer-Mediated Communication, 14(1): 1-34, https://doi.org/10.1111/j.1083-6101.2008.01429.x. 


$$
\text { المجلة الدولية للدراسـات التربوية والنفسية }
$$

International Journal of Educational \& Psychological Studies (EPS)

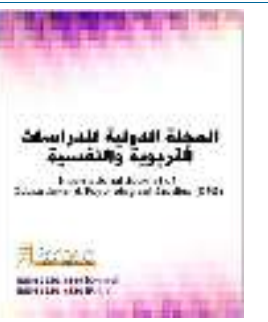

\title{
The relationship between the Big Five personality traits and the social media use
}

\author{
1Sharif Alsoudi, ${ }^{2}$ Raqiya Almatarafi, ${ }^{2}$ Alzahraa Alhussaini, ${ }^{2}$ Shama Almaqbali \\ ${ }^{1}$ Asisstant professor, College of Arts \& Humanities, Psychology department, A'Sharqiyah University, Oman. \\ ${ }^{2}$ Counseling student, College of Arts \& Humanities, Psychology department, A'Sharqiyah University, Oman. \\ ${ }^{1}$ Sharif.Alsoudi@asu.edu.om
}

Received : 14/3/2021 Revised:21/3/2021 Accepted : 25/3/2021 DOI : https://doi.org/10.31559/EPS2021.9.3.6

Abstract: The study aimed to discover the nature of the relationship between the Big Five personality traits and the usage of social media. The research sample of (528) male and female undergraduates from AL Sharqiyah university in the Sultanate of Oman distributed according to gender, academic level, and scientific college. The results indicated that the use of social media platforms was at a mediocre level with an average of (2.41) and at a percentage of $48 \%$. Moreover, the results demonstrated that agreeableness is the most common trait followed by openness to experience and conscientiousness, extraversion and neuroticism as the least common traits. Further results showed that there is a negative correlation between the degree of social media platform usage and agreeableness, and extraversion, as well as a positive correlation with openness to experience and neuroticism. In the analytical findings of the standard multiple linear regression, the data pointed that the personality traits explained up to $(27 \%)$ of the variety in social media platform use and all the personality traits had a statistical significance in predicting the degree of social media use.

Keywords: Big Five personality traits; social media, personality.

\section{References:}

1. Al'esymy, Sltan (2010). Edman Alentrnt W'laqth Baltwafq Alnfsy Alajtma'y Lda Tlab Almrhlh Althanwyh Bmdynh Alryad, [ Rsalh Majstyr Ghyr Mnshwrh]. Jam't Nayf Al'rbyh Ll'Iwm Alamnyh. Als'wdyh.

2. Almrkz Alwtny Llehsa' Walm'lwmat (2019). Asttla' Alray Hwl Wsa'l Altwasl Alajtma'y Fy Sltnh 'uman, Mtwfr 'br Alrabt: https://www.ncsi.gov.om/pages/ncsi.aspx.

3. Almwafy, F'ad Wwhysh, Ahmd Wzydan, 'sam Wmhmd, Mrwh (2014). Astkhdamat Alshbab Lmwaq' Altwasl Alajtma'y W'laqth Bal'waml Alkhmsh Alkbra Fy Alshkhsyh Ldy Tlab Aljam'h (Drash Wsfyh Thlylyh Lmstkhdmy Mwaq' Altwasl Alajtma'y). Mjlt Bhwth Altrbyh Alnw'yh: 8(34): 104-138.

4. Nwmar, Mrym Nryman (2017). Astkhdam Mwaq' Alshbkat Alajtma'yh Wtathyrh Fy Al'laqat Alajtma'yh: Drash 'ynh Mn Mstkhdmy Mwq' Alfysbwk Fy Aljza'r. [Rsalt Majstyr Ghyr Mnshwrh]. Klyt 'lwm Ale'lam Walatsal. Jam't Lkhdr. Aljza'r.

5. Alnwby, Mhmd 'ly (2010). Edman Alentrnt Fy 'sr Al'wlmh. Dar Sfa'. 'man.

6. Qdwrh, Swsn (2017). Astkhdam Mwaq' Altwasl Alaitma'y W'laqth Balshh Alnfsyh Wb'd Smat Alshkhsyh Lda Tlab Jam't Aljzyrh. [Rsalh Dktwrah Ghyr Mnshwrh]. Jam't Alkhrtwm. Alswdan.

7. Rady, Zahr (2003). Astkhdam Mwaq' Altwasl Alajtma'y Fy Al'alm Al'rby, Mjlt Altrbyh: Jam't 'Man Alahlyh. 1(15): 23-41.

8. S'wdy, 'bd Alkrym (2014). Edman Alfys Bwk W'laqth Baltwafq Alasry Lltalb Aljam'y, Drash 'la 'ynh Mn Jam't Bshar. Drasat Nfsyh Wtrbwyh: 19(13): 78-99.

9. Als'wdy, Shryf (Qyd Alnshr). Al'laqh Byn Mstwa Alqym Almadyh Wtqdyr Aldat Walshh Alnfsyh Lda Tlab Jam't Alshrqyh. Mjlt Drasat Nfsyh Wtrbwyh: Jam't Qasdy Mrbah Wrqlh. 